\title{
Increasing the Frequency of Spontaneous Rhythmic Activity Disrupts Pool-Specific Axon Fasciculation and Pathfinding of Embryonic Spinal Motoneurons
}

\author{
M. Gartz Hanson and Lynn T. Landmesser \\ Department of Neurosciences, Case Western Reserve University, School of Medicine, Cleveland, Ohio 44106-4975
}

\begin{abstract}
Rhythmic spontaneous bursting activity, which occurs in many developing neural circuits, has been considered to be important for the refinement of neural projections but not for early pathfinding decisions. However, the precise frequency of bursting activity differentially affects the two major pathfinding decisions made by chick lumbosacral motoneurons. Moderate slowing of burst frequency was shown previously to cause motoneurons to make dorsoventral $(\mathrm{D}-\mathrm{V})$ pathfinding errors and to alter the expression of molecules involved in that decision. Moderate speeding up of activity is shown here not to affect these molecules or $\mathrm{D}-\mathrm{V}$ pathfinding but to strongly perturb the anteroposterior (A-P) pathfinding process by which motoneurons fasciculate into pool-specific fascicles at the limb base and then selectively grow to muscle targets. Resumption of normal frequency allowed axons to correct the A-P pathfinding errors by altering their trajectories distally, indicating the dynamic nature of this process and its continued sensitivity to patterned activity.
\end{abstract}

Key words: axon guidance; spinal cord; motoneuron pool; spontaneous activity; glycine; GlyT1 transporter

\section{Introduction}

During development of the nervous system, axons make a series of orderly pathfinding decisions based on their interpretation of a complex array of molecular signals received from targets, intervening tissue, and other axons (Dickson, 2002; Chilton, 2006). However, once axons have reached their targets, electrical activity has been shown to influence a number of developmental processes, including cell survival, intramuscular nerve branching, and synaptic maturation (Pittman and Oppenheim, 1978; Thompson, 1983; Dahm and Landmesser, 1988; Busetto et al., 2000) (for review, see Moody and Bosma, 2004). Activity also has been shown to play a role in refining neural connections that were initially formed in response to molecular signals (Penn et al., 1998; Rossi et al., 2001; Stellwagen and Shatz, 2002; Grubb et al., 2003; Kim and Kandler, 2003; McLaughlin et al., 2003; Cang et al., 2005; Chandrasekaran et al., 2005; Tao and Poo, 2005).

Although activity has not been thought to enter into early pathfinding decisions (Katz and Shatz, 1996; Sengpiel and Kind, 2002), lowering the frequency of rhythmic activity in chick spinal cords, while motor axons are making dorsoventral (D-V) pathfinding decisions, was recently shown to result in $\mathrm{D}-\mathrm{V}$ pathfinding errors (Hanson and Landmesser, 2004), and the downregu-

Received Sept. 22, 2006; revised 0ct. 27, 2006; accepted 0ct. 30, 2006.

This work was supported by National Institutes of Health-National Institute of Neurological Disorders and Stroke Grants NS19640 and NS23678 and by National Institute of Child Health and Human Development postdoctoral training support T32HD07104 (M.G.H.).

Correspondence should be addressed to Lynn T. Landmesser, Department of Neurosciences, Case Western Reserve University, 10900 Euclid Avenue, Cleveland, 0H 44106-4975. E-mail: lynn.landmesser@case.edu.

M. G. Hanson's present address: University of Colorado Health Sciences Center, 12800 East 19th Avenue, Aurora, C0 80045 .

DOI:10.1523/JNEUROSCI.4170-06.2006

Copyright $\odot 2006$ Society for Neuroscience $\quad$ 0270-6474/06/2612769-12\$15.00/0 lation of two molecules previously shown to contribute to accurate D-V pathfinding, polysialic acid (PSA) on neural cell adhesion molecule (NCAM) (Tang et al., 1992, 1994) and Eph receptor tyrosine kinase A4 (EphA4) (Helmbacher et al., 2000; Eberhart et al., 2002; Kania and Jessell, 2003). To better understand how the frequency of such rhythmic cord activity might interact with the molecular signals involved in different types of pathfinding decisions, we determined the consequence of increasing the frequency of rhythmic bursting episodes.

Although the primary excitatory drive for rhythmic bursting at these stages is acetylcholine (Milner et al., 1999; Hanson and Landmesser, 2003), GABAergic and glycinergic transmission, both of which are excitatory at these stages (Milner and Landmesser, 1999; Hanson and Landmesser, 2003, 2004), also contribute to the excitatory drive. Thus, preventing the uptake of endogenously released glycine by blocking the glycine transporter GlyT1 with sarcosine increased the frequency of bursting activity by a factor of two (Hanson and Landmesser, 2003; Ren and Greer, 2003).

Surprisingly, this increase had no effect on $\mathrm{D}-\mathrm{V}$ pathfinding or on the expression of PSA or EphA4, which as noted above were decreased by reducing episode frequency. However, the subsequent major pathfinding decision, during which axons emerging from multiple spinal nerves group together into pool-specific fascicles in the plexus and then pathfind to their specific muscles (Lance-Jones and Landmesser, 1981a), was severely compromised, resulting in major anteroposterior (A-P) pathfinding errors. If, however, activity was allowed to return to normal levels after A-P pathfinding errors had been made in the plexus, axons were able to correct their trajectories more distally in the limb and project to their original muscle. This observation suggests that the normal frequency of bursting episodes is required through- 
out the period of axon growth to their targets and that the molecular/cellular process affected by activity is quite dynamic. These observations also show that the precise frequency of the rhythmic bursting activity, rather than overall activity levels, is the critical variable.

\section{Materials and Methods}

Chronic drug treatments. As reported previously by Hanson and Landmesser (2004), white leghorn chick embryos were incubated until stage 18 (St 18). A square hole was cut into the shell, and after moistening the embryo with Tyrode's solution, the hole was surrounded by a lip of paraffin. An elongated pipette tip was placed through the paraffin with its tip centered over the chorio-allantoic membrane, and the hole was sealed with a glass coverslip. Twice a day, starting at stage 20 , the specific glycine uptake inhibitor sarcosine $(10 \mathrm{mg} / \mathrm{d})$ or the glycine receptor antagonist strychnine $(1 \mathrm{mg} / \mathrm{d})$, dissolved in sterile Tyrode's solution, was administered through the pipette until the desired stage. To allow for the resumption of normal activity, embryos were treated with sarcosine starting at $\mathrm{St}$ 20 and given the last treatment at St 24 .

Recording of spontaneous bursting episodes in an isolated spinal cordhindlimb preparation. As reported previously (Landmesser and O'Donovan, 1984a), embryos were decapitated, eviscerated, and dissected in cool continuously oxygenated Tyrode's solution for control embryos and for embryos that had recovered from early treatment with chronic sarcosine. The chronic sarcosine-treated embryos were superfused with Tyrode's containing $100 \mu \mathrm{M}$ sarcosine and those chronically treated with strychnine, with Tyrode's containing $5 \mu \mathrm{M}$ strychnine. A combination of strychnine and sarcosine was used for embryos chronically treated with both drugs. A ventral laminectomy was performed and tissue was cleared to reveal the spinal and muscle nerves. The preparation was then warmed $\left(30^{\circ} \mathrm{C}\right)$ and superfused with oxygenated Tyrode's solution with or without specific drugs. Fine-tip suction electrodes pulled from polyethylene tubing (PE-190; Clay Adams, Parsippany, NJ) recorded the nerve output via amplifiers (P15D; Grass Amplifier connected with FLA-01; Cygnus Technology, Delaware Water Gap, PA) directly on the computer with Axoscope 8 (Axoscope, Foster City, CA). Significance of data was evaluated by Student's $t$ test, which determined the $p$ value (SigmaPlot 2.0; Jandel, San Rafael, CA). A $p$ value below 0.05 was considered significant.

To determine the functional segmental innervation of the sartorius and femorotibialis muscles in control and sarcosine-treated embryos, individual spinal nerves (see Fig. 2A) were stimulated via a Grass S48 stimulator and Grass PSIU6B stimulus isolation unit (Grass Instruments, Quincy, MA) with single supramaximal stimuli from suction electrodes. The resultant compound action potentials were recorded simultaneously from the sartorius and femorotibialis muscles using polyethylene suction electrodes pulled from polyethylene tubing (PE-190; Clay Adams), and their amplitude was used to estimate the extent to which individual spinal nerves contributed to their activation.

To determine the motoneuron pool-specific bursting patterns of motoneurons in control or sarcosine-treated embryos, single stimuli were applied to the thoracic spinal cord. This produced an episode of bursting activity that was recorded from sartorius or femorotibialis muscle nerves via tight-fitting polyethylene suction electrodes. Such recordings are able to detect the firing of individual motor units. Extensive past studies (Landmesser and O'Donovan, 1984a,b; Rafuse et al., 1996) have demonstrated the highly stereotyped bursting patterns of each motoneuron pool and the maintenance of these patterns when motoneurons are forced to innervate foreign muscles (Landmesser and O'Donovan, 1984b; Rafuse et al., 1996). Similar recordings were also made from the novel nerves that innervated the sartorius muscle in the sarcosine recovery embryos.

Quantification of fluorescent immunostaining. As described previously by Hanson and Landmesser (2004), images were captured with a digital camera (Olympus MagnaFire, Olympus America, Melville, NY) using the MagnaFire 2.0 software and imported into MetaMorph Imaging Analysis software (4.0; Universal Imaging Corporation, West Chester, $\mathrm{PA})$. To compare changes in expression of the molecules of interest
(PSA-NCAM, EphA4), two channels of fluorescence were captured and aligned in a stack. The first channel consisted of an internal control to compensate for variability of section thickness, limb orientation, or the density of axons within each section. It generally consisted of neurofilament (NF-160) immunostaining, because this stained all axons equivalently and NF-160 expression did not differ between dorsal and ventral axons, or after sarcosine treatments. The internal control for PSA expression was NCAM expression, because it too did not differ between dorsal or ventral axons or after drug treatments. The second channel recorded levels of PSA or EphA4, which was then expressed as a ratio over the internal control. To compare the mean pixel intensity of the immunostained axons of interest under different conditions, we first made masks around each region of interest (ROI), for example the dorsal or ventral axon region. The software then calculated the mean pixel intensity for the region within each mask. To compensate for alteration in background levels, each mask was duplicated and shifted into a nonaxonal region of the tissue. This background value was subtracted from the value of the ROI.

Because the pictures from each channel were stacked, the masks from the internal control were transferred onto the ROI and background regions of the second channel. These mean pixel intensity values of the ROI of the second channel were subtracted from the mean pixel intensities of the background region. The mean pixel intensity of the second channel was then divided by that of the internal control to give a mean pixel intensity of the molecule of interest relative to internal control. Next, the ratios for the particular mean pixel intensity of the ROI were averaged for a number of sections from at least three different embryos. These values were then binned according to developmental stages. Last, within each stage of development, the averaged ratio of mean pixel intensity of the dorsal axons ROI in Tyrode's solution-treated control embryos was used to normalize all other ROIs from the different treatments. Significance was determined through ANOVA and Student's $t$ test.

Quantification of in ovo movement. To quantify in ovo movements, windowed eggs were removed from the incubator at specified stages for $10 \mathrm{~min}$, during which time the number of episodes of axial movement was recorded. An episode of axial movement consisted of one or more continuous axial movements; single movements occurred at St 23, whereas more complex movements occurred at latter developmental stages (i.e., at St 30, a continuous movement could continue for $30 \mathrm{~s}$ ). No fewer than five embryos were used per time point, with each embryo evaluated at least three times.

Labeling of motoneurons with dextran. This protocol is a modification of retrograde labeling that was described by Hanson and Landmesser (2004). St 30 chick sartorius, femorotibialis, or adductor muscles in isolated spinal cord-hindlimb preparations were injected with Dextran conjugated to either Alexa 488 or Alexa 546 fluorophor (Invitrogen, San Diego, CA) and incubated for $6 \mathrm{~h}$ at $32^{\circ} \mathrm{C}$ in oxygenated Tyrode's solution to allow for retrograde transport to motoneurons. For orthograde labeling, spinal nerves were injected with either dextran conjugate and incubated for $6 \mathrm{~h}$ at $32^{\circ} \mathrm{C}$ in oxygenated Tyrode's solution, which allowed for orthograde transport to the end of nerves within the limb. In some cases, retrograde labeling was performed with Di-I or Di-Asp (Invitrogen, Eugene, OR).

Whole mounts were photographed using a $6.3 \times$ objective on an upright Nikon (Tokyo, Japan) Microphot-FX. The embryos were fixed in $3.7 \%$ formaldehyde for $3 \mathrm{~h}$ at room temperature and then washed with PBS. The embryos were washed in 5\% sucrose-PBS for $1 \mathrm{~h}$, placed in $30 \%$ sucrose-PBS overnight at $4^{\circ} \mathrm{C}$, placed in a 1:1 mixture of $60 \%$ sucrose and tissue-freezing medium (Triangle Biomedical Sciences, Durham, NC), and then frozen in dry ice-cooled isopentane and cryostat sectioned at $-30^{\circ} \mathrm{C}$ at $16 \mu \mathrm{m}$ (Cryocut1800; Leica, Nussloch, Germany). For histograms, only spinal cords that had a full set of serial sections were counted.

Immunohistochemistry. In Dextran-injected embryos, frozen sections were incubated with antibodies against Islet1/2 [mouse, 39.4D5, Developmental Studies Hybridoma Bank, Iowa City, IA; or Lim 1, a gift from Dr. S. Pfaff (Salk Institute, La Jolla, CA)] overnight. The sections were incubated with Cy3 anti-goat and Cy2 anti-mouse secondary for $1.5 \mathrm{~h}$, depending on the dextran-conjugate used (Jackson ImmunoResearch, West Grove, PA), mounted using ProLong Antifade Kit (Invitrogen), 

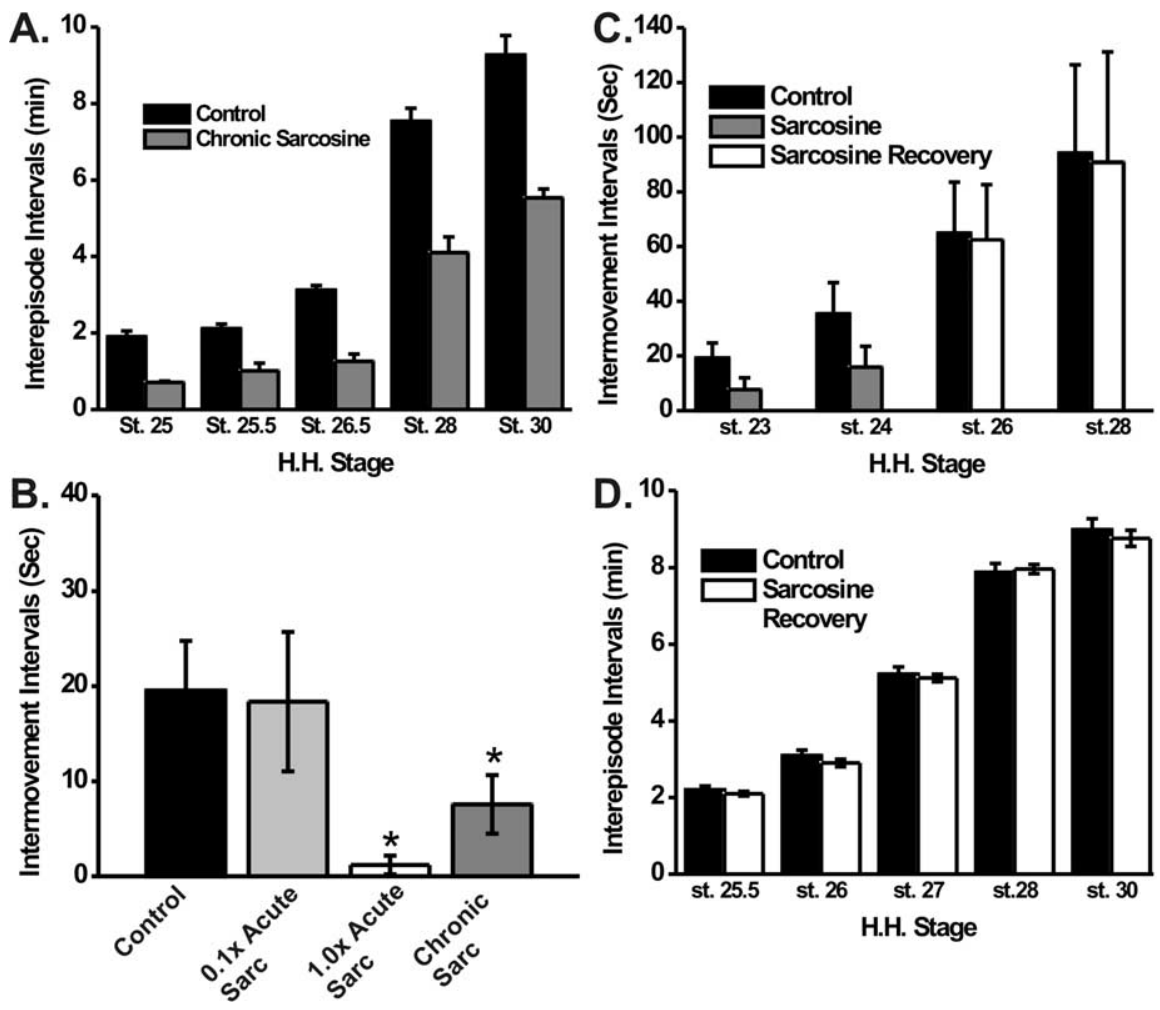

Figure 1. Intervals between episodes of spontaneous rhythmic activity in sarcosine-treated and control embryos. $A$, Bar graph of the intervals between electrically recorded episodes of activity in isolated cord preparations from control and chronic sarcosinetreated embryos at different developmental stages. The sarcosine-treated cords were dissected and recorded in Tyrode's containing $100 \mu \mathrm{m}$ sarcosine. $\boldsymbol{B}$, Bar graph of the intervals between in ovo movements quantified at $\mathrm{St} 23$ in control embryos and those treated acutely or chronically (from St 20) with sarcosine (Sarc). The 1.0X acute and chronic sarcosine values were significantly different from control $(p<0.05)$. C, When sarcosine treatment was stopped at $S t 24$, the intermovement intervals had returned to control values by $S t$ 26. D, The recovery to control values of interepisode intervals was also assessed with electrical recordings from isolated spinal cords at different developmental stages.

and visualized using MagnaFire 2.0 software (Olympus America) on an upright Nikon Microphot-FX. Procedures for immunostaining dorsal and ventral nerve trunks in the plexus with antibodies to PSA and EphA4 and for quantifying the immunofluorescence were described previously (Hanson and Landmesser, 2004).

\section{Results}

Chronic in ovo blockade of glycine uptake increases the frequency of spontaneous bursting episodes during motor axon outgrowth

To further test the necessity of maintaining the normal frequency of spontaneous rhythmic activity during early motoneuron axonal outgrowth, uptake of glycine was blocked by chronic [St 20-30, embryonic day 3 (E3) to E6.5] in ovo treatment with an inhibitor of the GlyT1 glycine transporter, sarcosine (Eulenburg et al., 2005). Chronic in ovo sarcosine treatment increased the frequency, or decreased the interepisode intervals, of rhythmic bursting episodes by approximately twofold from stage 25-30 (Fig. $1 A$ ), as assessed in the in vitro spinal-cord hindlimb preparations prepared from the treated embryos. The increase in episode frequency presumably resulted from preventing the reuptake of endogenously released glycine, which is excitatory at early stages of chick and mouse development (Wu et al., 1992; Nishimaru et al., 1996; Milner and Landmesser, 1999; Kulik et al., 2000; Hanson and Landmesser, 2003) and during the pathfinding events described here, which occur between St 22 and St 28.

Recently, spontaneous rhythmic episodes of activity were shown to occur as early as St 23 in the in vitro chick spinal cord preparation, a time when axons are making both dorsoventral and pool-specific pathfinding decisions during plexus formation (Hanson and Landmesser, 2004). Our previous studies also showed that this electrical activity was correlated with in ovo rhythmic s-shaped movements when axial muscles contract (limb muscles have not formed at this stage). Such axial movements could thus be used to document the in ovo effects of sarcosine treatment on rhythmic activity during this critical period of axon pathfinding. Both chronic and acute application of sarcosine decreased the interval between in ovo axial movements at these early stages (Fig. $1 B$ ). When the concentration of sarcosine, acutely applied in ovo, was reduced 10fold, there was no effect on movement frequency, suggesting that the concentration of sarcosine used in the chronic treatments was indeed in the physiological range.

If sarcosine treatment was discontinued after stage 24 , the in ovo intermovement intervals had increased to control values by St 26, when they were first assessed (Fig. 1C). Similarly, in cords isolated from such embryos, the interval between electrically recorded episodes had reached control values by St 25.5 (Fig. $1 D)$. Thus, we were able to assess the effect that such recovery of activity had on the subsequent behavior of motor axons that had already executed major pathfinding and fasciculation choices in the plexus region during the time of altered activity frequency.

\section{Spinal nerves failed to form a normal plexus during sarcosine treatment}

During the early formation of the spinal motor circuit (St 23-24), motor axons extend into the periphery from the spinal cord and make two important pathfinding decisions at the base of the limb in an area called the plexus region (Fig. $2 \mathrm{~A}$ ). The first major decision is for motor axons to defasciculate and sort into dorsal and ventral fascicles that contain the axons of lateral limbinnervating motoneurons (LMCls) and medial limb-innervating motoneurons (LMCms). This dorsoventral sorting begins within the individual spinal nerves and is complete before the convergence of the spinal nerves. Thus, dorsal and ventral rami in each spinal nerve physically diverge from one another before the convergence of the three to four spinal nerves that contribute to the crural plexus (Fig. 2A). At this point, these rami converge into separate dorsal and ventral trunks. Because most lumbosacral motoneuron pools extend over two to four cord segments, the second major decision requires that axons belonging to a single motor pool defasciculate from the axons of other pools within individual spinal nerves and then refasciculate with their poolspecific partners that have grown down other spinal nerves [the schematic diagram in Fig. $2 \mathrm{~A}$ shows the sartorius (green) and femorotibialis (red) axons executing this process]. Once poolspecific fascicles have formed, they remain tightly segregated and in stereotypic positions within the dorsal and ventral (obturator) 

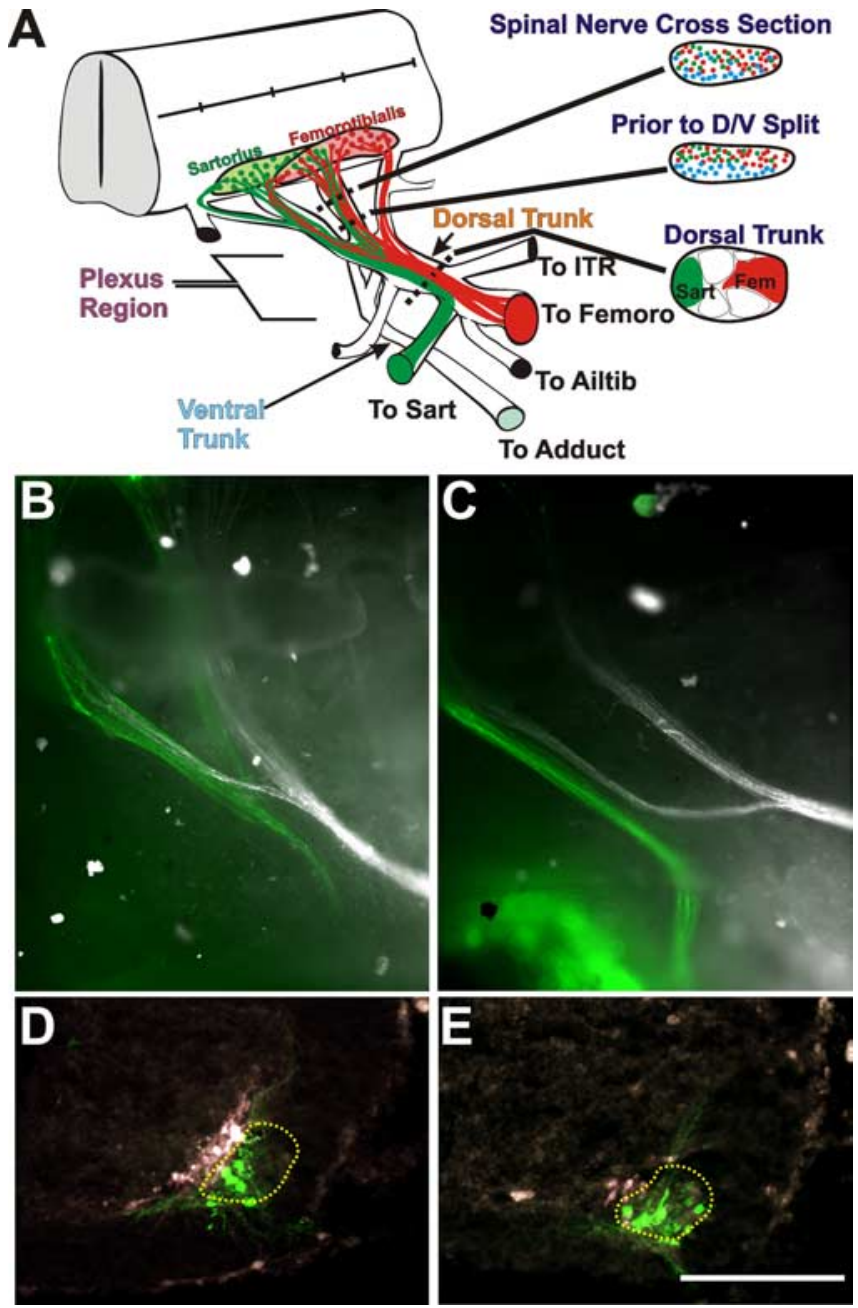

Figure 2. The sorting and pathfinding of axons that project to dorsal versus ventral limb muscles in control and sarcosine-treated embryos. $\boldsymbol{A}$, Diagram showing the reorganization and D-V pathfinding of two dorsal motoneuron pools (sartorius, green; femorotibialis, red). Cross sections at the right show the positions of these and ventrally projecting axons (blue) to the adductor (Adduct) muscle in the proximal spinal nerve where they are extensively intermingled (top), just before the convergence of spinal nerves into the crural plexus, where dorsal and ventral projecting axons have segregated along the D-V axis (middle) and within the dorsal (crural) nerve trunk after the ventral (obturator) trunk has diverged and sartorius (Sart) and femorotibialis (Fem) axons have formed discrete fascicles (bottom). The dorsal nerve trunk diverges to innervate multiple muscles (ITR, iliotrochanterici; Femoro, femorotibialis; Ailtib, anterior iliotibialis). The ventral trunk projects to the adductor muscle. $\boldsymbol{B}, \boldsymbol{C}$, Whole mounts as seen from the ventral surface of control and sarcosine-treated embryos, respectively, of axons retrogradely labeled with dextrans from the sartorius (green) and the adductor (white). Labeled axons are seen in spinal nerves $L S 1$ and $L S 2 . D, E$, Cross sections showing the ventral spinal cord on one side from control and sarcosine-treated embryos, respectively, at the level of LS1 (ventral, down; medial, left). In both cases, the sartorius motoneuron somas (green) are located lateral to those projecting to the adductor (white), in appropriate $\mathrm{LMCl}$ and $\mathrm{LMCm}$ locations, showing that D-V pathfinding has not been affected. The $L M C l$ is encircled with a dashed line. Scale bar, $100 \mu \mathrm{m}$.

nerve trunks until they diverge as individual muscle nerves (Fig. 2A) (see also Lance-Jones and Landmesser, 1981a).

In a previous study (Hanson and Landmesser, 2004), chronically slowing the frequency of rhythmic activity with the $\mathrm{GABA}_{\mathrm{A}}$ receptor antagonist picrotoxin resulted in dorsoventral pathfinding errors. Because we were able to increase the frequency of such episodes with sarcosine (Fig. $1 A, B$ ), we were able to address whether altering the frequency in the opposite direction would have either a quantitatively different or no effect on D-V path- finding, or whether it would alter some different aspect of motor axon pathfinding. In the chronic sarcosine-treated embryos, dorsal and ventral crural nerve trunks appeared to diverge appropriately. To determine whether some axons within these trunks had made D-V pathfinding errors, as we had previously found when the frequency of rhythmic activity was reduced (Hanson and Landmesser, 2004), the adductor (a ventral muscle) and the sartorius (a dorsal muscle) were retrogradely labeled with fluorescently tagged dextrans. As shown in the examples in Figure 2, B and $C$, axons projecting to the sartorius (green) segregated from those axons projecting to the adductor (white) in the plexus region. Importantly, all of the cell bodies of sartorius-projecting axons were located laterally in the $\mathrm{LMCl}$, whereas those labeled from the adductor muscle (white) were all located medially in the LMCm (Fig. 2D,E) with no overlap similar to controls. In addition, as in control embryos, sartorius motoneurons were all Lim $1+$ and islet $1 / 2-$, as were femorotibialis motoneurons, whereas the converse was true for adductor motoneurons (Table 1). Thus, neither D-V somal migration errors nor D-V pathfinding errors were made when the frequency of spontaneous bursting activity was increased. In addition, we observed that the expression of two candidate molecules for producing the $\mathrm{D}-\mathrm{V}$ pathfinding errors, EphA4 and PSA, which were decreased when the episode frequency was decreased, were unaffected, by increasing the frequency. The mean normalized pixel intensity of immunostained nerves at the plexus region at St 25 for EphA4 was $1.00 \pm 0.04$ in control and $1.07 \pm 0.11$ in sarcosine-treated embryos (intensities were normalized to the dorsal nerve of control embryos) (see Materials and Methods for additional details). Similarly, the normalized values for PSA staining on the dorsal trunk $(1.00 \pm 0.07$ for control and $1.05 \pm 0.09$ for sarcosine treated) as well as on the ventral trunk $(0.37 \pm 0.08$ for control and $0.40 \pm 0.10$ for sarcosine) and did not differ significantly $(p<0.05)$.

However, despite the normal dorsoventral pathfinding, plexus formation and muscle nerve-specific pathfinding were severely altered. The sartorius normally receives its innervation from LS1 and LS2 with a very minor contribution from T7. In contrast, the femorotibialis receives most of its innervation from LS2 and LS3 with a minor contribution from LS1 (Landmesser, 1978; Matise and Lance-Jones, 1996). Thus, sartorius axons in LS2 must defasciculate from the axons of the femorotibialis and other pools and refasciculate with sartorius axons from LS1 (Fig. 2A). Similarly, femorotibialis axons in LS1 must diverge and regroup with their pool-specific partners in LS2 and 3. This normal sorting of axons can be visualized by retrogradely labeling the axons projecting to the sartorius and femorotibialis with green and red dextrans, respectively (Figs. 3A, $2 B$ ).

In the chronic sarcosine-treated embryos (Fig. $3 B$ ), the three spinal nerves converged anatomically into a plexus, although this generally occurred more distally than normal. However, the axons within LS1 and LS2 did not intermingle with each other in the plexus, with the result that the LMCl axons in LS1 remained tightly fasciculated and most, if not all, projected to the sartorius muscle (Figs. $3 B$, green axons, $2 C$ ). Similarly, most of the $\mathrm{LMCl}$ axons in LS2 projected to the femorotibialis. The distribution of retrogradely labeled motoneuron somas in the spinal cord confirmed these observations, as seen both in spinal cord whole mounts (data not shown) and in histograms from transversely sectioned cords (Fig. $3 D, E$ ) that plot the distribution of neurons retrogradely labeled from the sartorius and femorotibialis along the A-P axis in control and sarcosine-treated embryos, as a percentage of the total number labeled for each pool. This perturbation of A-P pathfinding was profound as the large number of 
Table 1. Number of retrogradely labeled motoneurons in each spinal cord segment projecting to the sartorius, femorotibialis, and adductor muscles and their expression of the LIM transcription factors islet $1 / 2$ and Lim 1 in control and sarcosine-treated embryos

\begin{tabular}{|c|c|c|c|c|c|c|}
\hline \multirow[b]{2}{*}{ Injected muscle $(n=3)$} & \multirow{2}{*}{$\begin{array}{l}\text { Total labeled } \\
\text { motoneurons }\end{array}$} & \multicolumn{3}{|c|}{ Motoneurons } & \multirow{2}{*}{$\begin{array}{l}\text { Proportion } \\
\text { of } \operatorname{Lim} 1+\end{array}$} & \multirow{2}{*}{$\begin{array}{l}\text { Proportion } \\
\text { of Islet } 1+\end{array}$} \\
\hline & & LS1 & $\mathrm{LS} 2$ & LS3 & & \\
\hline \multicolumn{7}{|l|}{ Control } \\
\hline \multirow[t]{3}{*}{ Sartorius } & 131 & 83 & 48 & 0 & (120) 92\% & $0(0 \%)$ \\
\hline & 111 & 87 & 24 & 0 & (103) 93\% & $0(0 \%)$ \\
\hline & 76 & 55 & 21 & 0 & (69) 91\% & $0(0 \%)$ \\
\hline \multirow[t]{3}{*}{ Femorotibialis } & 172 & 34 & 85 & 51 & (151) 88\% & $0(0 \%)$ \\
\hline & 143 & 20 & 79 & 44 & (130) 91\% & $0(0 \%)$ \\
\hline & 125 & 19 & 71 & 35 & (116) 93\% & $0(0 \%)$ \\
\hline \multirow[t]{3}{*}{ Adductor } & 83 & 46 & 37 & 0 & $0(0 \%)$ & (77) 93\% \\
\hline & 74 & 35 & 39 & 0 & $0(0 \%)$ & (61) $83 \%$ \\
\hline & 55 & 22 & 33 & 0 & $0(0 \%)$ & (48) $87 \%$ \\
\hline \multicolumn{7}{|l|}{ Chronic Sarcosine } \\
\hline \multirow[t]{3}{*}{ Sartorius } & 128 & 115 & 6 & 0 & (116) 91\% & $0(0 \%)$ \\
\hline & 114 & 103 & 4 & 0 & (105) 92\% & $0(0 \%)$ \\
\hline & 96 & 89 & 6 & 0 & (84) $87 \%$ & $0(0 \%)$ \\
\hline \multirow[t]{3}{*}{ Femorotibialis } & 138 & 3 & 131 & 3 & (127) 92\% & $0(0 \%)$ \\
\hline & 142 & 6 & 132 & 4 & (126) $89 \%$ & $0(0 \%)$ \\
\hline & 87 & 7 & 78 & 2 & (75) $86 \%$ & $0(0 \%)$ \\
\hline \multirow[t]{3}{*}{ Adductor } & 78 & 34 & 44 & 0 & $0(0 \%)$ & (72) $92 \%$ \\
\hline & 82 & 58 & 24 & 0 & $0(0 \%)$ & (73) $89 \%$ \\
\hline & 62 & 13 & 49 & 0 & $0(0 \%)$ & (53) $86 \%$ \\
\hline
\end{tabular}

now projected to the femorotibialis (Fig. $3 F$ ), similar to the control pool (Fig. 3D). These observations suggest that after rhythmic activity returned to normal, many of the motor axons were able to correct the pathfinding errors by taking novel trajectories distal to the plexus.

\section{The sarcosine-induced anatomical alterations in plexus formation are reflected in altered functional input to muscles}

Shortly after target innervation (St 30), EMG recordings from individual muscles with suction electrodes allow one to determine the extent to which different spinal nerves activate each muscle. This has been shown previously to be approximately proportional to the number of motor axons projecting to that muscle (Landmesser and Morris, 1975; Landmesser, 1978). The example from a control, Tyrode's-injected embryo (Fig. 4A) shows that stimulation of spinal nerves LS1 and LS2 produced compound action potentials in the sartorius with

motoneurons that normally project to the femorotibialis from LS3 no longer did so. Similarly, the substantial number of sartorius motoneurons in LS2 no longer projected to the sartorius (compare histograms in Fig. 3D,E).

Supporting the idea that most of the $\mathrm{LMCl}$ motoneurons in LS1 now projected to the sartorius and most in LS2 projected to the femorotibialis were the spatial distributions of the retrogradely labeled somas observed in cross sections in which islet$1 / 2$ expression (white) was used to demarcate all of the ventrally projecting motoneurons belonging to $\mathrm{LMCm}$ (Fig. 3G,H). In general, the sartorius and femorotibialis pools from the sarcosine-treated embryos were not as discrete as in controls and had labeled cell bodies distributed throughout the LMCl. Additionally, as indicated by the counts in Table 1, the total number of motoneurons projecting to the sartorius from LS1 in sarcosinetreated embryos was increased compared with control values. There was a similar increase in the number of neurons projecting to the femorotibialis from LS2.

\section{Pathfinding errors are partially corrected after the resumption of spontaneous activity}

Plexus formation and pool-specific axon sorting takes place between St 23 and St 25. To determine whether the fasciculation/ pathfinding errors produced by sarcosine treatment were permanent or whether they could be corrected, the pattern of fasciculation was assessed in embryos in which sarcosine treatment had been stopped at St 24, and the frequency of spontaneous bursting had returned to control values by St 25.5. As shown in Figure $3 C$, at the plexus region, which we have defined as the convergence of spinal nerves LS2 and 3 (white arrowheads), the sartorius projecting axons in LS2 (green, arrow) did not join with the sartorius axons in LS1 as in the control (Fig. $3 A$ ) but continued to associate with the red axons projecting to the femorotibialis (Fig. 3C). However, more distally, they took a novel pathway and projected to the sartorius. As would be expected, motoneurons retrogradely labeled from the sartorius could now be found in LS2 (Fig. 3F) where they extended as far posterior as in the control pool (Fig. 3D). In addition, motoneurons in LS1 and LS3 the greatest contribution from LS1. In contrast, the femorotibialis muscle was predominantly activated by LS2 and LS3 with a minor contribution from LS1 $(n=15)$.

In the chronic sarcosine-treated embryos $(n=12)$, LS2 no longer activated the sartorius, which received all of its functional innervation from LS1. Similarly, the femorotibialis in this embryo was predominantly activated by a single spinal nerve, LS2. LS1 did not activate the femorotibialis muscle, and only rarely (1 in 12 sarcosine-treated embryos) did stimulation of LS3 produce a response (Fig. $4 B$ ), and this was quite small (Fig. 4B). These data show that axons, which have anatomically projected to inappropriate muscles after sarcosine treatment, also form functional synapses with those muscles. Finally, when rhythmic activity was allowed to recover by stopping sarcosine treatment at St 25, the EMG recordings (Fig. 4C) supported the anatomical findings presented in Figure 3, which showed that a number of the axons that had made sorting errors had corrected their trajectory somewhere distal to the plexus, which occurred in all embryos tested $(n=7)$.

\section{Motoneurons that innervate foreign muscles in sarcosine- treated embryos maintain their original pool-specific bursting patterns}

The data presented thus far suggest that most of the LMCl motoneurons in LS2, including those that would have originally projected to the femorotibialis as well as those that would have projected to the sartorius, now innervated the femorotibialis. Similarly, femorotibialis motoneurons in LS1 now appeared to project to the sartorius. To asses whether other aspects of motor pool identity, including pool-specific bursting patterns, were unaltered by sarcosine treatment, indicating that these axons had simply made pathfinding errors, or whether their pool identity had been transformed by the treatment, we made muscle nerve recordings from control and sarcosine-treated embryos at St 30, when pool-specific bursting patterns are clearly distinguishable.

The sartorius is a flexor, and the femorotibialis is an extensor, and thus they are activated out of phase with each other (Fig. 5A) during spontaneous bursting episodes from St 30 (E7) (Land- 
messer and O'Donovan, 1984a; O’Donovan, 1989). At St 30, each spontaneous episode consists of multiple bursts, and each burst (a single burst is shown in Fig. $5 B$ ) begins with a brief synchronous activation of both motor pools, after which the femorotibialis bursts, whereas the sartorius is prevented from firing by GABA acting on $\mathrm{GABA}_{\mathrm{A}}$ receptors (O'Donovan, 1989). After this inhibitory period (Fig. $5 A$, top trace, black bar), the sartorius usually exhibits a prolonged burst (top trace, asterisk) that often lasts until the next femorotibialis burst, whereas the femorotibialis is silent during this period (bottom trace, arrowhead) ( $n=9$ for control recordings). Previous studies have shown that when embryonic chick motoneurons were surgically forced to innervate foreign muscles, they maintained their original pool-specific bursting patterns (Landmesser and O'Donovan, 1984b; Rafuse et al., 1996), which result from a combination of intrinsic membrane properties and central connectivity. Thus, if motoneurons did not have their identities altered in the sarcosine-treated embryos but simply projected to the wrong muscle, one would expect to see, when recording from the sartorius, that femorotibialis motoneurons would burst during the sartorius inhibitory period. Similarly, when recording from the femorotibialis, one would expect to find sartorius motoneurons continuing to burst after the normal cessation of the femorotibialis burst.

These observations were in fact made. In contrast to the clean inhibitory period observed in all nine control sartorius muscles (Fig. 5B, top trace, bar), units can be seen firing during this period in the sarcosine-treated embryos (Fig. 5C, top trace, arrow). In addition, units continued to fire in the femorotibialis muscle after the time that the burst in this muscle would normally cease; a large number of units burst simultaneously with the highamplitude portion of the sartorius burst, and many continued to burst late in the cycle, typical of sartorius motoneurons (Fig. 5C, bottom trace, arrowhead). The relative amplitude of bursts during a recording reflects the number of units firing. Thus, given that the number of femorotibialis motoneurons in LS1 is relatively small, this likely accounts for the lower amplitude of the burst during the sartorius inhibitory period. Similar findings were seen in every chronic sarcosinetreated embryo $(n=11)$. Allowing recovery of activity in sarcosine-treated embryos after St 24 resulted in a reduced
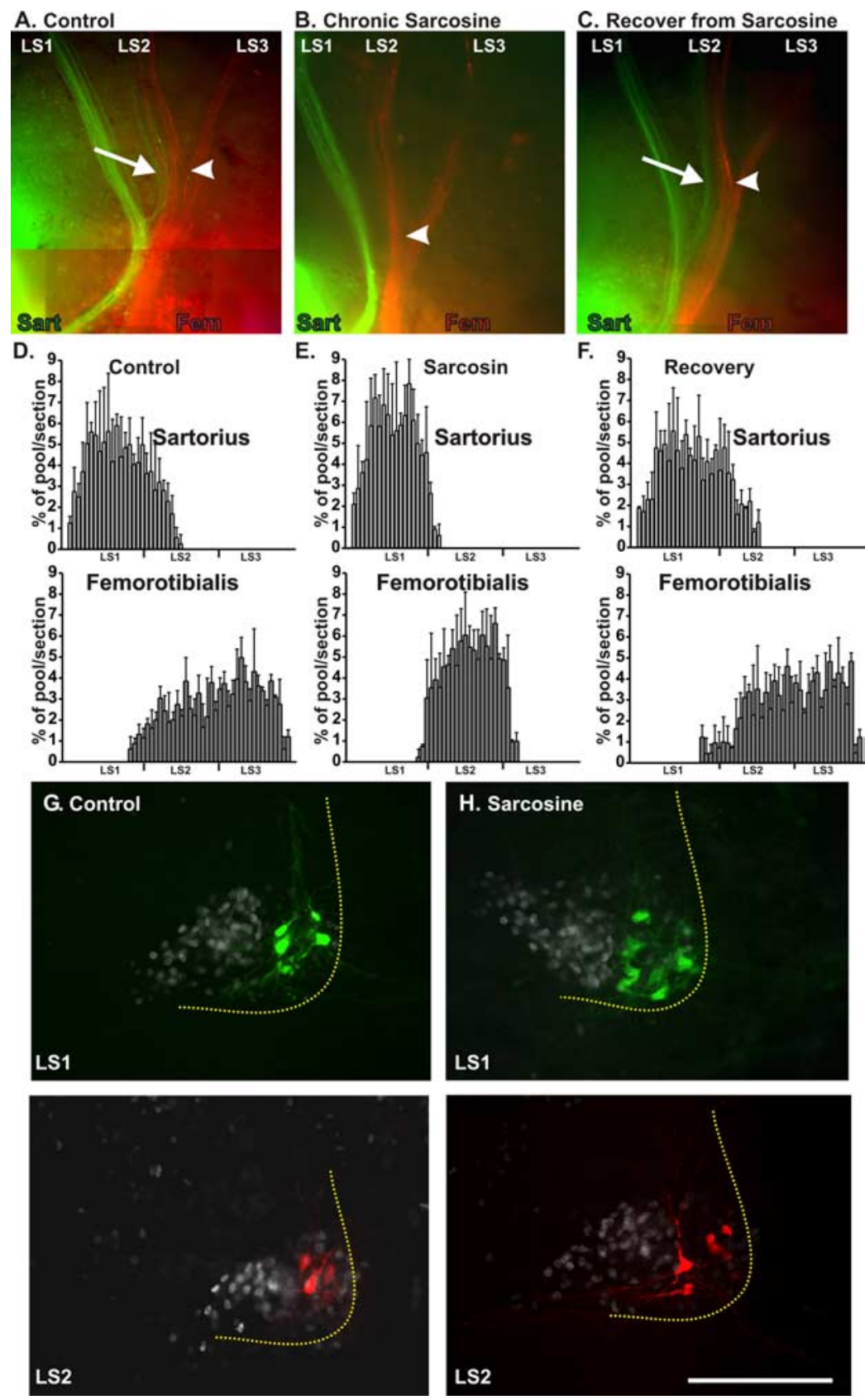

Figure 3. Motoneuron pool-specific pathfinding in control embryos, those treated with sarcosine, and those in which sarcosine treatment was stopped at St 24 (sarcosine recovery) and activity was allowed to recover to control values. $\boldsymbol{A}-\boldsymbol{C}$, Whole mounts of control, sarcosine, and sarcosine recovery embryos in which axons projecting to the sartorius (Sart; green) and femorotibialis (Fem; red) were retrogradely labeled at St 30 by fluorescent dextrans. White arrows show green labeled axons in spinal nerve LS2 projecting to the sartorius in control $(\boldsymbol{A})$ and sarcosine recovery $(\boldsymbol{C})$ but not in embryos treated with sarcosine throughout the growth of axons from the spinal cord to their entry into the muscle $(\boldsymbol{B})$. The plexus region, where spinal nerves LS2 and LS3 converge, is marked by a white arrowhead. In the control embryo $(\boldsymbol{A})$, the sartorius labeled axons in LS2 diverge at this point to join the sartorius axons in LS1 (red labeled axons projecting to the femorotibialis were also present in LS1 but cannot be distinguished in this whole mount at this level of magnification). With chronic sarcosine treatment, no axons from LS2 project to the sartorius $(\boldsymbol{B})$. When sarcosine treatment was stopped after plexus formation $(\boldsymbol{C})$, the sartorius-labeled axons fail to diverge at this point and continue to grow with the femorotibialis axons (red) toward the femorotibialis muscle. However, more distally, they diverge and grow to the sartorius muscle. $\boldsymbol{D}-\boldsymbol{F}$, Histograms of the rostrocaudal location of motoneuron somas retrogradely labeled from the sartorius (top) and femorotibialis (bottom) quantified from serial frozen sections and expressed as the percentage of the total number of neurons in each pool ( 3 embryos/histogram). The sartorius pool extends into LS2 in the control and sarcosine recovery but not with chronic sarcosine. Similarly, the femorotibialis pool extends into LS1 and LS3 in control and sarcosine recovery but not sarcosine. $\mathbf{G}, \boldsymbol{H}$, The location of motoneuron somas retrogradely labeled from the sartorius (green, top) at the level of LS1 or from the femorotibialis (red, bottom) at the level of LS2. The sections were also immunostained with antibody for islet $1 / 2$, which labels the nuclei of all LMCm motoneurons. In the sarcosine-treated embryos, all sartorius and femorotibialis somas were located lateral to the $\mathrm{LMCm}$, consistent with a lack of D-V pathfinding errors. However, in general, the somas of each pool were distributed throughout the $\mathrm{LMCl}$, rather than being clustered in distinct locations. 
A. St. 30 Control
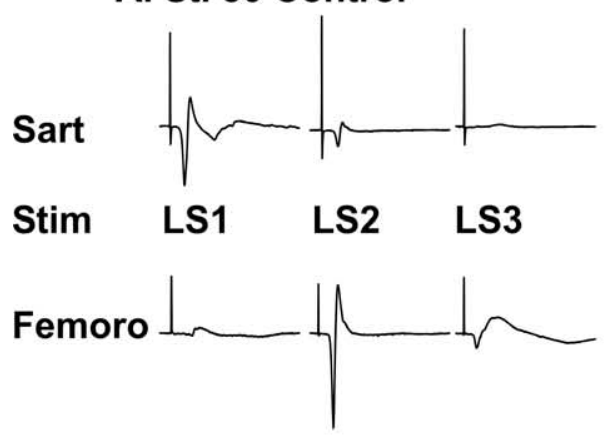

B. St. 30 Chr. Sarc
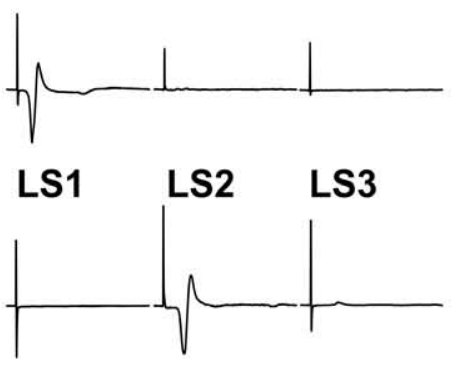

C. St. 30 Sarc Recovery

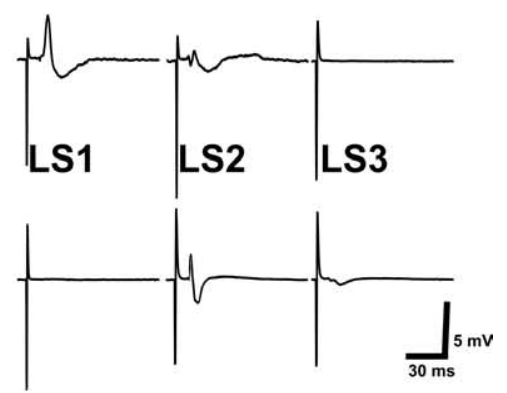

Figure 4. EMG recordings reveal the functional innervation of sartorius (Sart) and femorotibialis (Femoro) muscles by different spinal cord segments in control, sarcosine, and sarcosine recovery embryos. The amplitude of EMG responses, in response to a single maximal stimulus (Stim) to each spinal nerve, shows that the functional segmental innervation by the three spinal nerves that compose the crural plexus is altered in the chronic (Chr) sarcosine (Sarc) treatment $(\boldsymbol{B})$ compared with control $(\boldsymbol{A})$, but that recovery of activity after cessation of sarcosine treatment at $\mathrm{St} 24$ restores the segmental innervation pattern toward control values. Calibration: $30 \mathrm{~ms}, 5 \mathrm{mV}$.

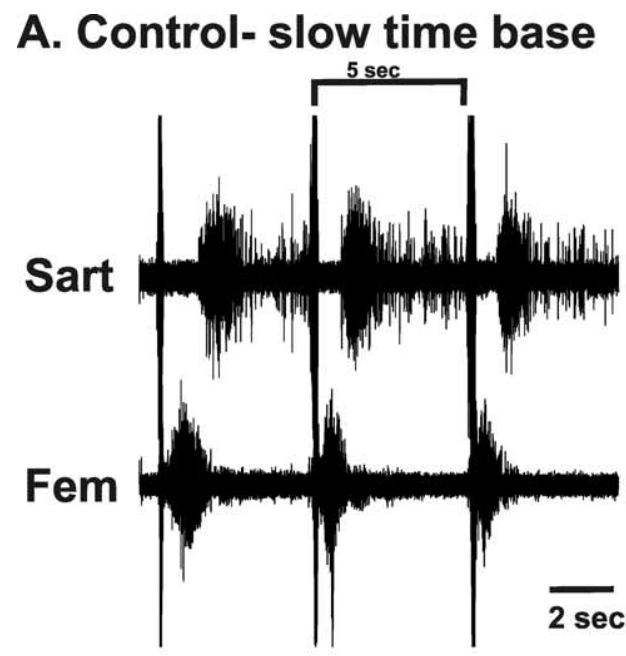

\section{B. Control- burst}

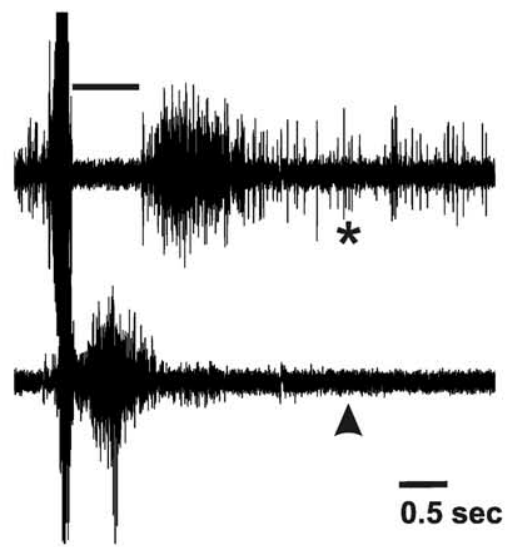

\section{Sarcosine-burst}

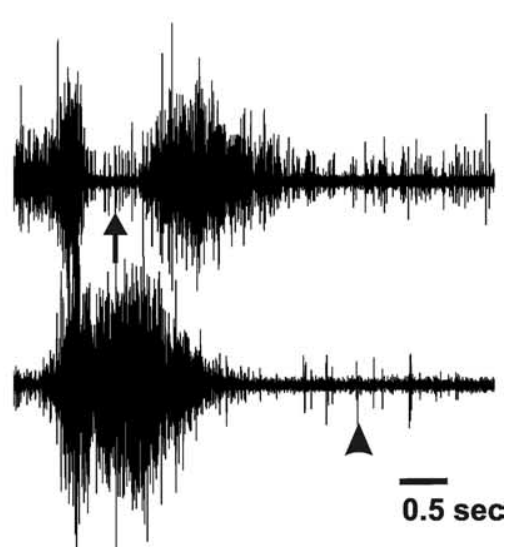

Figure 5. Muscle nerve recordings reveal that motoneurons that have innervated foreign muscles retain their original pool-specific bursting patterns. $\boldsymbol{A}$, Recordings of an episode of activity induced by a single stimulus to the thoracic cord from control sartorius (Sart; top) and femorotibialis (Fem; bottom) nerves show that these are activated out of phase in the three "step" cycles that comprise an episode of activity at St 30. The bracket delineates one cycle in the top trace. After a brief activation, the sartorius exhibits a period of inhibition during which the femorotibialis fires. Subsequently, the sartorius resumes bursting until the next cycle. $\boldsymbol{B}, \boldsymbol{C}$, Expanded time base traces of a single cycle in control $(\boldsymbol{B})$ and sarcosine $(\boldsymbol{C})$-treated embryos. The arrowhead in $\boldsymbol{C}$ denotes units in the femorotibialis nerve firing during the normal sartorius inhibitory period (shown by a bar in the top trace of $\boldsymbol{B}$ ). The arrowhead in $\boldsymbol{C}$ shows units firing in the sarcosine-treated femorotibialis muscle during the prolonged period of the sartorius burst in the control ( $\boldsymbol{B}$, asterisk), whereas no units fire during this time in the control femorotibialis ( $\boldsymbol{B}$, arrowhead).

number of units firing during the sartorius inhibitory period (data not shown), consistent with the data presented previously that axons were able to correct their trajectories somewhere distal to the plexus.

Resumption of normal rhythmic activity in sarcosine-treated embryos is correlated with motor axons correcting their pathfinding defects via the formation of novel aberrant nerves

If motor axons have corrected their trajectory after plexus formation, this would have to occur by axons taking novel trajectories distal to the plexus via the formation of aberrant nerves (LanceJones and Landmesser, 1981b). To identify such aberrant nerves, LS1 and LS2 were injected with green and red dextrans, respectively, in St 30 control embryos and in sarcosine-treated embryos allowed to recover spontaneous activity. Although both motor and sensory axons are labeled by spinal nerve injections, the highly stereotyped anatomical pattern of limb nerves in control embryos revealed the existence of such aberrant nerves. In the control embryo shown in Figure 6A, LS2 had been injected with a red dextran, and the divergence of some of those axons into the sartorius nerve (trajectory indicated by green dashed line) is clear (control embryos injected, $n=15$ ). In contrast, in the sarcosinetreated embryo (Fig. 6B), no axons diverged from LS2 at the normal point of divergence of the sartorius muscle nerve (dashed green line). However, more distally, a novel nerve (arrow) diverged from the crural nerve trunk and projected into the sartorius muscle and occurred in every embryo that recovered its spontaneous activity $(n=10)$. Such novel nerves were also detectable when dissections were made for nerve recording. However, they varied widely from animal to animal; in some cases, one or two fairly large nerves diverged and were clearly distinguishable, whereas in other cases, axons diverged at numerous points, forming many very fine nerves that were difficult to visualize under the dissecting microscope.

To determine the location of the motoneurons that had projected axons to the sartorius via these aberrant nerves, we labeled the sartorius muscle with dextran (Fig. 6C, green axons in diagram) and cut spinal nerve LS1 (severing LS1 axons that had projected to the sartorius via the normal route). Thus, all labeled 
somas should belong to LS2 motoneurons that had projected to the sartorius via these novel nerves. As shown in the histograms of Figure $6 B$, such motoneurons were distributed in LS2 along the rostrocaudal axis similar to the control sartorius pool (control embryos, $n=6$; sarcosine recovery embryos, $n=6$ ). They were also located in the LMCl (Fig. $6 \mathrm{H}$, green cells, LMCl denoted by dashed yellow line), and although many were very ventral in the location of the normal sartorius pool at this level (Fig. 6I), some were located more dorsally where they were mixed with somas (red cells) labeled from the femorotibialis (Fig. $6 \mathrm{H}$ ). This alteration may indicate a modest effect of activity on the aggregation of $\mathrm{LMCl}$ motoneurons into discrete nuclei.

Because of this finding, it was important to determine whether such aberrant nerves were formed by sartorius axons responding to specific guidance cues or whether they might be formed by axons arising from multiple motoneuron pools. Therefore, suction electrode recordings were made from aberrant nerves (Fig. 6E), which are also labeled $\mathrm{E}$ in the diagram in Figure $6 C$, whereas simultaneously recording from the sartorius nerve (Fig. $6 D)$. The recording from the sartorius nerve (Fig. 6D) reveals a bursting pattern that is essentially like the control sartorius (Fig. 5A, top trace) in that it exhibits long bursts interrupted by a clear inhibitory period (Fig. 6, bracket). However, as shown previously (Fig. 5C), units, presumably femorotibialis, also burst during the inhibitory period. The bursting patterns recorded from aberrant nerves in sarcosine recovery embryos, as in the example shown (Fig. 6E), were clearly sartorius in nature, with clean inhibitory periods (Fig. $6 E$, bracket) and with units continuing to burst (asterisk) during the period of the prolonged sartorius burst. Thus, the axons that had created these aberrant nerves appeared to be sartorius.

Recordings made from the femorotibialis muscle nerve proximal and distal to where the aberrant nerves diverged to the sartorius supported this conclusion. Distal recordings (Fig. 6F) exhibited relatively clean femorotibialis patterns with short bursts and little activity during the prolonged sartorius burst period (bracket). However, more proximal recordings (Fig. 6G) revealed many units, presumably sartorius, bursting during this period, which was similar to the sarcosine-treated embryo shown in Figure $5 C$. These experiments were replicated multiple times $(n=5)$ with similar results. These data, when combined with the histological data, strongly suggest that the aberrant nerves were comprised of axons that should have projected to the muscles recorded from, and were thus likely responding to specific guidance cues within the limb.

I. femorotibialis pool.
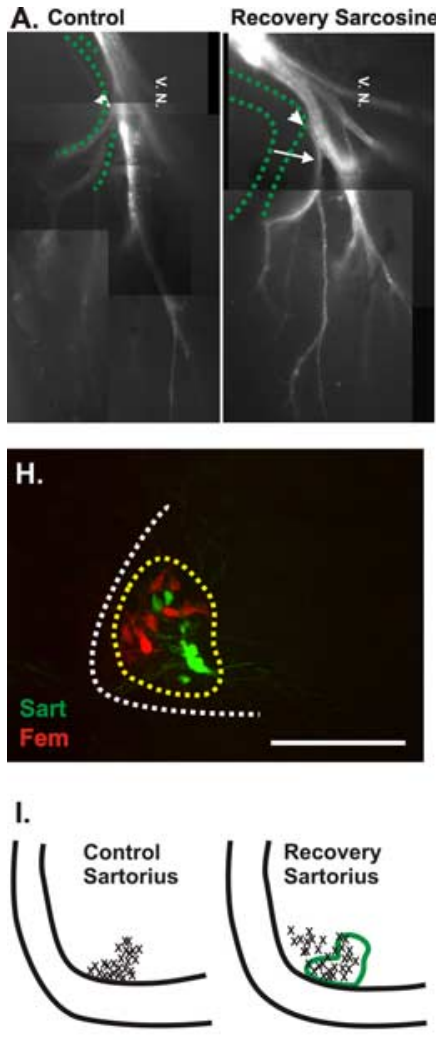

Figure 6. Sartorius axons that made pathfinding errors in the plexus after sarcosine treatment are able to correct these errors via the formation of novel distal nerves when sarcosine treatment is stopped and activity returns to normal levels. $\boldsymbol{A}, 0$ rthograde dashed green line) in the control (left). When the frequency of activity was altered by sarcosine treatment until St 24 (right), LS2 axons failed to project into the sartorius nerve (location shown by dashed green line), but after resumption of activity axons from LS2 formed novel nerves (arrow) that diverged more distally to project to the sartorius muscle. $\boldsymbol{B}$, After transection of spinal nerve LS1 and injection of the sartorius muscle with a dextan dye, the motoneuron cell bodies of axons that projected to the sartorius muscle via the novel aberrant nerves were found to extend throughout spinal segment LS2, similar to the control sartorius pool. Histograms show the number of motoneurons at different rostrocaudal levels from serial frozen cross sections of cord, expressed as the percentage of the total labeled pool. C, A diagram to show the formation of novel aberrant nerves projecting to the sartorius (sart axons green, femoro axons red). $\boldsymbol{D}-\boldsymbol{G}$, Nerve recordings from the sartorius nerve $(\boldsymbol{D})$, an aberrant nerve $(\boldsymbol{E})$, and at differen patters with a clear inhibitory period (bracket) and prolonged unit activity (asterisk) until the next cycle. Recordings from the pattern, whereas recordings distal to this point showed a cleaner femorotibialis pattern $(\boldsymbol{F})$, with units no longer firing during the prolonged sartorius bursting period (brackets, compare $\boldsymbol{F}$ and $\boldsymbol{G}$ ). $\boldsymbol{H}$, The location of cell bodies in LS2 retrogradely labeled via encircles the $\mathrm{LMCl}$, whereas the white dashed line indicates the lateral boundary of the ventral cord. Scale bar, $100 \mu \mathrm{m}$. I, The ocation of all LS2 cell bodies retrogradely labeled from the sartorius from one sarcosine recovery embryo and projecting to the recovery embryo are in the location of the control pool (green line), some appear to be displaced and in the location of the

\section{Pathfinding defects are prevented when embryos were} simultaneously treated with sarcosine and strychnine We assumed that the alterations in the frequency of activity and the resultant pathfinding defects are caused by the enhanced effect of endogenously released glycine acting on glycine receptors. To provide evidence for this and to exclude other nonspecific effects of sarcosine, strychnine, which inhibits glycine receptors (Young and Snyder, 1973; Goldinger et al., 1981), was given in ovo together with sarcosine from St 20 to St 30. We had shown previously that chronic strychnine treatment alone did not affect dorsoventral or muscle-specific pathfinding decisions (Hanson and Landmesser, 2004). In the present study, we first observed that strychnine prevented the sarcosine-induced increase in the 

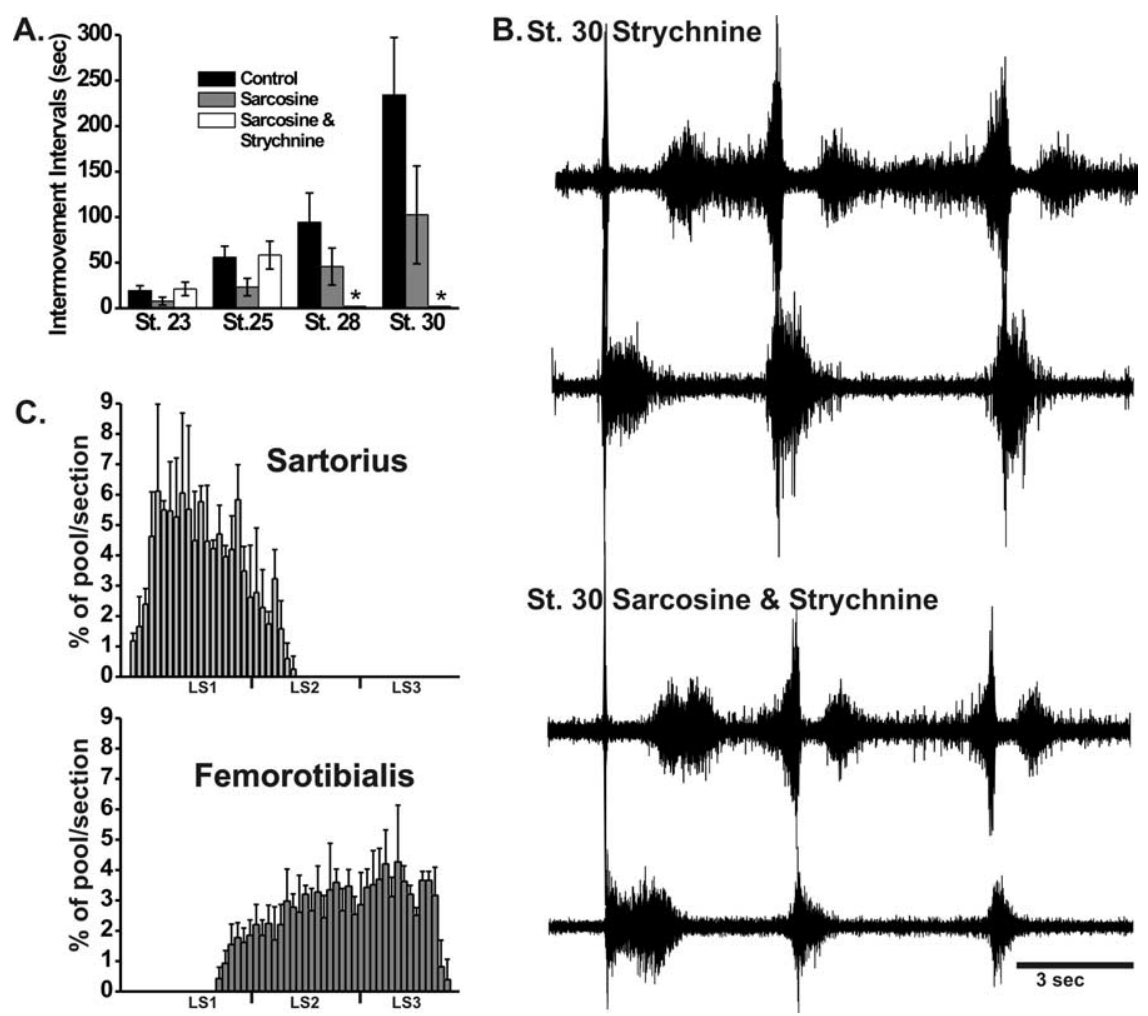

Figure 7. The effect of sarcosine on the frequency of spontaneous episodes and on pool-specific pathfinding errors is prevented by simultaneous application of the glycine receptor antagonist strychnine. A, In ovo intermovement intervals in control, sarcosineand combined sarcosine/strychnine-treated embryos. $B$, EMG recordings in isolated St 30 cord preparations after washout of drugs reveal control-like bursting patterns in the strychnine-treated (top) and combined sarcosine/strychnine (bottom)-treated embryos. In each pair of traces, the sartorius is on the top, and the femorotibialis is on the bottom. $\boldsymbol{C}$, After the combined strychnine/ sarcosine treatment, the location of sartorius and femorotibialis pools are unaltered from control levels showing that A-P pathfinding errors produced by sarcosine alone have been prevented.

frequency of rhythmic activity (Fig. 7A) from St 23 to St 25. Consistent with previous observations (Hanson and Landmesser, 2004), only at later stages (St 28-30) when muscles nerves had already projected to their muscles did strychnine block spontaneous activity. We found that strychnine prevented the sarcosine-induced pathfinding errors, with both sartorius and femorotibialis motoneuron pools exhibiting their normal locations in the lumbar cord (Fig. 7C). Finally, after drug washout from cords isolated from strychnine/sarcosine-treated embryos both the sartorius and femorotibialis exhibited normal bursting patterns with no unit activity during the inhibitory period of the sartorius (Fig. $7 B$ ). These results, taken together, suggest that the pathfinding errors produced by chronic sarcosine treatment were attributable to increased glycinergic transmission via strychninesensitive glycine receptors.

\section{Discussion}

The observations presented here, when combined with our previous study (Hanson and Landmesser, 2004), indicate that moderately increasing or decreasing the frequency of spontaneous bursting episodes has robust but different effects on the two major pathfinding decisions made by lumbosacral motoneurons: the binary decision to project dorsally or ventrally and the subsequent motoneuron pool/muscle-specific fasciculation of axons in the plexus and their selective growth to the appropriate muscle. These results strongly suggest that the rhythmic pattern of wavelike activity, which we have shown occurs at very early stages of spinal motor circuit formation in both the chick and mouse (Hanson and
Landmesser, 2003, 2004), interacts with the molecular signaling cascades that regulate downstream guidance decisions.

The episodes of rhythmic propagating activity in the early spinal cord share many similarities with retinal waves. In the visual system of both mice and rodents, a number of recent papers have confirmed the importance of the normal pattern of retinal waves in the proper targeting of axons in the lateral geniculate, superior colliculus, and visual cortex (Penn et al., 1998; Stellwagen and Shatz, 2002; McLaughlin et al., 2003; Cang et al., 2005; Chandrasekaran et al., 2005; Torborg et al., 2005) (for review, see Torborg and Feller, 2005). Although the precise molecular mechanisms underlying the effects of altered activity on visual projections is not well understood, the mechanism is thought to involve Hebbian or spike timing-dependent competitive interactions between visual afferents as they compete for synaptic space in target structures (Hebb, 1949; Zhang et al., 1998; Ruthazer and Cline, 2006). Such a mechanism is unlikely to contribute to the early pathfinding errors we detected after altering activity, because these occur while motor axons are just growing into the limb and before any contact with muscle targets. Another way in which patterned activity could affect pathfinding is by altering the expression of molecules involved in either the $\mathrm{D}-\mathrm{V}$ or the motoneuron pool-specific pathfinding decisions. Below, we discuss each of these pathfinding decisions and how they might be affected by activity.

\section{Dorsoventral pathfinding errors}

Slowing the frequency of activity episodes, which affected D-V but not A-P pathfinding, resulted in the downregulation of PSA on NCAM and of the ephrin receptor EphA4, both of which have been implicated in D-V pathfinding (Tang et al., 1992, 1994; Helmbacher et al., 2000; Eberhart et al., 2002; Kania and Jessell, 2003). Slowing activity did not affect a number of other motor axon cell surface molecules, including NCAM itself, L1/NgCAM, or the receptor tyrosine phosphatase CRYP $\alpha$ (Hanson and Landmesser, 2004; our unpublished observations). It is of interest that when the frequency of activity episodes was increased, as demonstrated in the present study, neither $\mathrm{D}-\mathrm{V}$ pathfinding nor the expression of PSA or EphA4 was altered. The downregulation of PSA or of EphA4 has not yet been shown to be causal for the D-V pathfinding errors we observed, and in fact even simple binary decisions such as the $\mathrm{D}-\mathrm{V}$ motor axon choice are likely to involve multiple molecules and pathways as demonstrated recently ( $\mathrm{Hu}-$ ber at al., 2005; Kramer et al., 2006). Nevertheless, the data, taken together, support this possibility and also emphasizes the distinct nature of the $\mathrm{D}-\mathrm{V}$ and pool-specific fasciculation/pathfinding choices, although both are performed in the same approximate location (mesenchyme surrounding distal spinal nerves and plexus) and at approximately the same time (although the $\mathrm{D}-\mathrm{V}$ decision slightly precedes the A-P decision). 


\section{A-P/motoneuron pool-specific fasciculation and pathfinding errors}

Increasing the frequency of episodes of activity produced striking alterations in the pool-specific convergence of axons in the plexus and their subsequent selective growth to target muscles. Because this process likely involves selective fasciculation based on attractive and/or repulsive cell surface molecules on axons as well as on the axons' selective responses to guidance cues from the muscle targets, it is molecularly complex. The complex patterns of Eph/ ephrin expression in motoneurons have been hypothesized to contribute to motoneuron pool-specific guidance (Cohen et al., 2005). Additionally, hox genes and their cofactors recently have been shown to be involved in specifying motoneuron pool identity, including peripheral connectivity (Dasen at al., 2005). However, the downstream guidance molecules that enable poolspecific pathfinding are currently unknown. Nevertheless, poolspecific pathfinding was severely compromised when activity was increased. Axonal growth per se and subsequent synapse formation were not impaired, resulting in muscles being innervated by a mixture of appropriate and foreign motoneurons.

Previous studies have shown that after surgical A-P displacements or rotations of the neural tube, many axons were able to reach their correct muscle although they grew out different spinal nerves (Lance-Jones and Landmesser, 1981b). For example, many sartorius axons that had entered the sciatic plexus, which supplies the posterior thigh, projected to the anterior sartorius muscle by taking novel pathways through the limb that were very similar to the novel nerves observed in the sarcosine recovery animals. It was suggested that the response of axons to targetderived diffusible guidance cues was the only reasonable explanation for such novel nerve formation. Of interest, FGF has recently been identified as a target-derived chemoattractant that selectively attracts medial motor column axons to their axial muscle target region (Shirasaki et al., 2006). The selective defects in motoneuron pool/muscle-specific pathfinding that we observed would be expected to occur if the alterations in activity prevented motoneuron growth cones from responding to such muscle-specific chemoattractants, possibly by affecting a common intracellular signaling pathway. Alterations in the expression of guidance cues could also have occurred. However, although we focused on two muscles, the A-P pathfinding defects were widespread, occurring in both the crural and sciatic plexi, and this would require alterations in the expression of multiple guidance cues or their receptors, and we thus favor the previous explanation.

Changes in activity also might have altered the identity of motoneurons. Although the transcription factors that specify sartorius and femorotibialis pool identity are unknown, a number of transcription factors have been shown to be expressed in a poolspecific pattern (Lin et al., 1998), and hox genes and their cofactors have been shown recently to contribute to the A-P specification of motoneurons (Shah et al., 2004; Dasen et al., 2005). However, the maintenance of the original pool-specific bursting patterns by the sarcosine-treated sartorius and femorotibialis motoneurons and the fact that these motoneurons were able to correct their trajectories to reach their appropriate target muscles when activity resumed is evidence that pool identities were not altered.

In early Xenopus spinal cord, chronic alterations in the level of spontaneous activity produced by drugs or by exogenously expressed ion channels were recently shown to change the proportion of neurons expressing either excitatory (ACh, glutamate) or inhibitory (GABA, glycine) transmitters because of an apparent compensatory homeostatic response (Borodinsky et al., 2004). We did not observe such alterations after chronic picrotoxin or sarcosine treatments, and the frequency and pharmacology of the activity that rapidly resumed (within $30 \mathrm{~min}$ to several hours) after the washout of drugs from cords isolated from treated embryos was not different from controls. Possible explanations for these different findings are species differences, differences in developmental stage, or the fact that the modest changes in the frequency of activity produced in our studies was insufficient to trigger such homeostatic mechanisms.

\section{What aspects of rhythmic bursting activity are regulating specific motoneuron pathfinding decisions?}

During bursting episodes, motoneurons are strongly depolarized in a rhythmic pattern. There is precedent for such strong, temporally spaced stimuli to activate specific intracellular signaling pathways (Wu et al., 2001). Furthermore both the pattern and frequency of stimulation and ensuing $\mathrm{Ca}^{2+}$ transients can regulate neuronal gene expression (Dolmetsch et al., 1997; Itoh et al., 1997; Watt et al., 2000). Thus, the frequency of the bursting episodes may be the critical variable to which motoneurons are responding. However, because motoneurons are embedded in a circuit, during bursting episodes, motoneuron depolarization and increases in intracellular $\mathrm{Ca}^{2+}$ will be accompanied by the release of the transmitters ACh, GABA, and Glycine and possibly of trophic factors such as BDNF (Meyer-Franke et al., 1998; AlMajed et al., 2000; Chang and Berg, 2001; Balcowiec and Katz, 2002; Berghuis et al., 2004). Several transmitters such as GABA and glycine have been shown to affect early developmental processes, including neuronal proliferation and migration (for reviews, see Nguyen et al., 2001; Owens and Kriegstein, 2002). Thus, it will be important to determine whether signaling though transmitter receptors plays any role in the alterations in pathfinding that we have observed. One way that this might be accomplished would be by driving bursting episodes via in ovo activation with light of electroporated Channel rhodopsin 2. Such an approach would enable bursting episodes to be elicited at different frequencies (Li et al., 2005) in the presence or absence of specific transmitter antagonists. In any case, the observations we made demonstrate the importance of maintaining the normal frequency of rhythmic activity in embryos during early pathfinding decisions and thus indicate caution in that any drugs that may alter rhythmic activity in early embryogenesis, including those that affect cholinergic, GABAergic or glycinergic transmission may impair the development of spinal motor and, perhaps, other circuits.

\section{References}

Al-Majed AA, Brushart TM, Gordon T (2000) Electrical stimulation accelerates and increases expression of BDNF and trkB mRNA in regenerating femoral motoneurons. Eur J Neurosci 12:4381-4390.

Balcowiec A, Katz DM (2002) Cellular mechanisms regulating activitydependent release of native brain-derived neurotrophic factor from hippocampal neurons. J Neurosci 22:10339-10407.

Berghuis P, Dobszay MB, Sousa KM, Schulte G, Mager PP, Hartig W, Gores TJ, Zilberted Y, Ernfors P, Harkany T (2004) Brain-derived neurotrophic factor controls functional differentiation and microcircuit formation of selectively isolated fast-spiking GABAergic interneurons. Eur J Neurosci 20:1290-1306.

Borodinsky LN, Root CM, Cronin JA, Sann SB, Gu X, Spitzer NC (2004) Activity-dependent homeostatic specification of transmitter expression in embryonic neurons. Nature 429:523-530.

Busetto G, Buffelli M, Tognana E, Bellico F, Cangiano A (2000) Hebbian mechanisms revealed by electrical stimulation at developing rat neuromuscular junctions. J Neurosci 20:685-695. 
Cang J, Renteria RC, Kaneko M, Liu X, Copenhagen DR, Stryker MP (2005) Development of precise maps in visual cortex requires patterned spontaneous activity in the retina. Neuron 48:797-809.

Chandrasekaran AR, Plas DT, Gonzalez E, Crair MC (2005) Evidence for an instructive role of retinal activity in retinotopic map refinement in the superior colliculus of the mouse. J Neurosci 25:6929-6938.

Chang KT, Berg DK (2001) Voltage-gated channels block nicotinic regulation of CREB phosphorylation and gene expression in neurons. Neuron 32:855-865.

Chilton JK (2006) Molecular mechanisms of axon guidance. Dev Biol 292:13-24.

Cohen S, Funkelstein L, Livet J, Rougon G, Henderson CE, Castellani V, Mann F (2005) A semaphorin code defines subpopulations of spinal motor neurons during mouse development. Eur J Neurosci 21:1767-1776.

Dahm LM, Landmesser LT (1988) The regulation of intramuscular nerve branching during normal development and following activity blockade. Dev Biol 130:621-644.

Dasen JS, Tice BC, Brenner-Morton S, Jessell TM (2005) A hox regulatory network establishes motor neuron pool identity and target-muscle connectivity. Cell 123:477-491.

Dickson BJ (2002) Molecular mechanisms of axon guidance. Science 298:1959-1964.

Dolmetsch RE, Lewis RS, Goodnow CC, Healy JI (1997) Differential activation of transcription factors induced by $\mathrm{Ca}^{2+}$ response amplitude and duration. Nature 386:855-858.

Eberhart J, Swartz ME, Koblar SA, Pasquale EB, Krull CE (2002) EphA4 constitutes a population-specific guidance cue for motor neurons. Dev Biol 247:89-101.

Eulenburg V, Armsen W, Betz H, Gomeza J (2005) Glycine transporters: essential regulators of neurotransmission. Trends Biochem Sci 30:325-333.

Goldinger A, Muller WE, Wollert U (1981) Inhibition of glycine and GABA receptor binding by several opiate agonists and antagonists. Gen Pharmacol 12:477-479.

Grubb MS, Rossi FM, Changeux JP, Thompson ID (2003) Abnormal functional organization in the dorsal lateral geniculate nucleus of mice lacking the beta 2 subunit of the nicotinic acetylcholine receptor. Neuron 40:1161-1172.

Hanson MG, Landmesser LT (2003) Characterization of the circuits that generate spontaneous episodes of activity in the early embryonic spinal cord. J Neurosci 23:587-600.

Hanson MG, Landmesser LT (2004) Normal patterns of spontaneous activity are required for correct motor axon guidance and the expression of specific guidance molecules. Neuron 46:687-701.

Hebb DO (1949) The organization of behavior. New York: Wiley.

Helmbacher F, Schneider-Maunoury S, Topilko P, Tiret L, Charney P (2000) Targeting of the EphA4 tyrosine kinase receptor affects dorsal/ventral pathfinding of limb motor axons. Development 127:3313-3324.

Huber AB, Kania A, Tran TS, Gu C, De Marco Garcia N, Lieberam I, Johnson D, Jessell TM, Ginty DD, Kolodkin AL (2005) Distinct roles for secreted semaphorin signaling in spinal motor axon guidance. Neuron 48:949-964.

Itoh K, Ozaki M, Stevens B, Fields RD (1997) Activity dependent regulation of $\mathrm{N}$-cadherin in DRG neurons: differential regulation of $\mathrm{N}$-cadherin, NCAM, and L1 by distinct patterns of action potentials. J Neurobiol 33:735-748.

Kania A, Jessell TM (2003) Topographic motor projections in the limb imposed by LIM homeodomain protein regulation of ephrin-A: EphA interactions. Neuron 38:581-596.

Katz LC, Shatz CJ (1996) Synaptic activity and the construction of cortical circuits. Science 274:1133-1138.

Kim G, Kandler K (2003) Elimination and strengthening of glycinergic/ GABAergic connections during tonotopic map formation. Nat Neurosci 6:282-290.

Kramer ER, Knott L, Su F, Dessaud E, Krull CE, Helmbacher F, Klein R (2006) Cooperation between GDNF/Ret and ephrinA/EphA4 signals for motor-axon pathway selection in the limb. Neuron 50:35-47.

Kulik A, Nishimaru H, Ballanyi K (2000) Role of bicarbonate and chloride in GABA- and glycine-induced depolarization and $\left[\mathrm{Ca}^{2+}\right] \mathrm{I}$ rise in fetal rat motoneurons in situ. J Neurosci 20:7905-7913.

Lance-Jones C, Landmesser L (1981a) Pathway selection by chick lumbosa- cral motoneurons during normal development. Proc R Soc Lond B Biol Sci 214:1-18.

Lance-Jones C, Landmesser LT (1981b) Pathway selection by embryonic chick lumbosacral motoneurons in an experimentally altered environment. Proc R Soc Lond B Biol Sci 214:19-52.

Landmesser LT (1978) The distribution of motoneurons supplying chick hind limb muscles. J Physiol (Lond) 284:371-389.

Landmesser LT, Morris DG (1975) The development of functional innervation in the hindlimb of the chick embryo. J Physiol (Lond) 249:301-326.

Landmesser LT, O’Donovan MJ (1984a) Activation patterns of embryonic chick hind limb muscles recorded in-ovo and in an isolated spinal cord preparation. J Physiol (Lond) 347:189-204.

Landmesser LT, O’Donovan MJ (1984b) The activation patterns of embryonic chick motoneurons projecting to inappropriate muscles. J Physiol (Lond) 347:205-224.

Li X, Gutierrez DV, Hanson MG, Han J, Mark MD, Chiel H, Hegemann P, Landmesser LT, Herlitze S (2005) Fast non-invasive activation and inhibition of neural and network activity by vertebrate rhodopsin and green algae channel rhodopsin. Proc Natl Acad Sci USA 102:17816-17821.

Lin JH, Saito T, Anderson DJ, Lance-Jones C, Jessell TM, Arber S (1998) Functionally related motor neuron pool and muscle sensory afferent subtypes defined by co-ordinate ETS gene expression. Cell 95:393-407.

Matise MP, Lance-Jones C (1996) A critical period for the specification of motor pools in the chick lumbosacral spinal cord. Development 122:659-669.

McLaughlin T, Torborg CL, Feller MB, O’Leary DD (2003) Retinotopic map refinement requires spontaneous retinal waves during a brief critical period of development. Neuron 40:1147-1160.

Meyer-Franke A, Wilkinson GA, Kruttgen A, Hu K, Munro E, Hanson MG, Reichardt LF, Barres BA (1998) Depolarization and camp elevation rapidly recruit TrkB to the plasma membrane of CNS neurons. Neuron 21:681-693.

Milner LD, Landmesser LT (1999) Cholinergic and GABAergic inputs drive patterned spontaneous motoneuron activity before target contact. J Neurosci 19:3007-3022.

Moody WJ, Bosma MM (2004) Ion channel development, spontaneous activity, and activity-dependent development in nerve and muscle cells. Physiol Rev 85:883-941.

Nguyen L, Rigo J-M, Rocher V, Belachew S, Malgrange B, Rogister B, Leprince P, Moonen G (2001) Neurotransmitters as early signals for central nervous system development. Cell Tissue Res 305:187-202.

Nishimaru H, Iizuki S, Ozaki S, Kudo N (1996) Spontaneous motoneuronal activity mediated by glycine and GABA in the spinal cord of rat fetuses in vitro. J Physiol (Lond) 497:132-143.

O’Donovan MJ (1989) Motor activity in the isolated spinal cord of the chick embryo: synaptic drive and firing properties of single motoneurons. J Neurosci 9:943-958.

Owens DF, Kriegstein AR (2002) Developmental neurotransmitters? Neuron 36:989-995.

Penn AA, Riquelme PA, Feller MB, a Shatz CJ (1998) Competition in retinogeniculate patterning driven by spontaneous activity. Science 279:2108-2112.

Pittman RH, Oppenheim RW (1978) Neuromuscular blockade increases motoneurone survival during normal cell death in the embryo. Nature 271:425-446.

Rafuse VF, Milner L, Landmesser LT (1996) Selective innervation of fast and slow muscle regions during early chick neuromuscular development. J Neurosci 16:6864-6877.

Ren J, Greer JJ (2003) Ontogeny of rhythmic motor patterns in the embryonic rat spinal cord. J Neurophysiol 89:1187-1195.

Rossi FM, Pizzorusso T, Porciatti V, Marubio LM, Maffei L, Changeux JP (2001) requirement of the nicotinic acetylcholine receptor $\beta 2$ subunit for the anatomical and functional development of the visual system. Proc Natl Acad Sci USA 98:6453-6458.

Ruthazer ES, Li J, Cline HT (2006) Stabilization of axon branch dynamics by synaptic maturation. J Neurosci 26:3594-3603.

Sengpiel F, Kind PC (2002) The role of activity in development of the visual system. Curr Biol 12:R18-R26.

Shah V, Drill E, Lance-Jones C (2004) Ectopic expression of Hoxd10 in thoracic spinal segments induces motoenurons with lumbosacral molecular profile and axon projections to limb. Dev Dyn 231:43-56.

Shirasaki R, Lewcock JW, Lettieri K, Pfaff SL (2006) FGF as a target derived 
chemoattractant for developing motor axons genetically programmed by the LIM code. Neuron 50:841-853.

Stellwagen D, Shatz CJ (2002) An instructive role for retinal waves in the development of retinogenicuate connectivity. Neuron 33:357-367.

Tang J, Landmesser L, Rutishahuser U (1992) Polysialic acid influences specific pathfinding by avian motoneurons. Neuron 8:1031-1044.

Tang J, Rutishauser U, Landmesser L (1994) Polysialic acid regulates growth cone behavior during sorting of motor axons in the plexus region. Neuron 13:405-414.

Tao HW, Poo M-m (2005) Activity-dependent matching of excitatory and inhibitory inputs during refinement of visual receptive fields. Neuron 45:829-836.

Thompson WJ (1983) Synapse elimination in neonatal rat muscle is sensitive to the apttern of muscle use. Nature 302:614-616.

Torborg CL, Feller MB (2005) Spontaneous patterned retinal activity and the refinement of retinal projections. Prog Neurobiol 76:213-235.

Torborg CL, Hansen KA, Feller MB (2005) High frequency, synchronized bursting drives eye-specific segregation of retinogeniculate projections. Nat Neurosci 8:72-78.

Watt SD, Gu X, Smith RD, Spitzer NC (2000) Specific frequencies of spontaneous $\mathrm{Ca} 2+$ transients upregulate GAD 67 transcripts in embryonic spinal neurons. Mol Cell Neurosci 16:376-387.

Wu GY, Deisseroth K, Tsien RW (2001) Spaced stimuli stabilize MAPK pathway activation and its effects on dendritic morphology. Nat Neurosci 4:151-158.

Wu W, Ziskind-Conhaim L, Sweet MA (1992) Early development of glycine- and GABA-mediated synapses in rat spinal cord. J Neurosci 12:3935-3945.

Young AB, Snyder SH (1973) Strychnine binding associated with glycine receptors of the central nervous system. Proc Natl Acad Sci USA 70:2832-2836.

Zhang, Tao HW, Holt CE, Harris WA, Poo M (1998) A critical window for cooperation and competition among developing retinotectal synapses. Nature 395:37-44. 